\title{
Implicaciones Tafonómicas y Zooarqueológicas del Paleolítico inferior de la Península lbérica
}

José Yravedra Sainz de los Terreros.

Departamento de Prehistoria e Historia Antigua de la UNED

Av. De Alberto Alcocer 47. 28016 Madrid 913598233 jyravedra@teleline.es

\section{Resumen}

En este trabajo se realiza un análisis de la subsistencia en el Paleolítico Inferior de la Península Ibérica, con la finalidad de delimitar que agentes intervinieron en las acumulaciones óseas de dicho periodo. Tras este estudio se ha visto como sólo los yacimientos del interior muestran un número representativo, y en ellos se describen dos tipos de yacimientos. Los primeros serían de carácter fluviolacustre con predominio de paquidermos y el trienio, cérvidos, équidos y bóvidos, mientras que los segundos son emplazamientos sobre cuevas con predominio del trienio aludido. Finalmente los datos tafonómicos parecen revelar un acceso cárnico importante entre los homínidos del Pleistoceno Medio, aunque nuevos análisis tafonómicos más meticulosos deberán aportar una información más contrastada.

Palabras Clave. Paleolítico Inferior, Tafonomía, Marcas de corte, Carnívoros.

\begin{abstract}
In this paper the subsistence of the Iberian Peninsula at lower Paleolithic is discussed for to show the different agents that assemblage bones in this moment. Only the inside sites are representative, and its included two types of assemblages. The first ones are sites fluvial environment with predominance of elephants, horses, bovids and red deer, while in the second sites are caves and detach the red deer, horses and bovids. Finality the taphonomy studies to indicate diet meat rich in the hominids from the Middle Pleistocene.
\end{abstract}

Keywords. Lower Paleolithic, Taphonomy, Cut Marcs, Carnivorous.

\section{INTRODUCCIÓN}

En este trabajo se presenta una síntesis bibliográfica de los estudios zooarqueológicos desarrollados en el Paleolítico Inferior de la Península Ibérica, en total se analiza la información de 20 yacimientos con sus respectivos niveles (Figura 1).

Para poder analizar esta información se ha dividido la Península Ibérica en tres regiones, comprendidas la primera por la Cornisa cantábrica, la segunda por el interior y la fachada atlántica y una tercera limitada a la vertiente mediterránea. De estas tres áreas sólo el Interior peninsular ha ofrecido un conjunto de yacimientos lo suficientemente amplio, como para poder establecer conclusiones significativas.

Desde un punto de vista metodológico la información que va a tratarse se referirá al $N R$ (Número de restos) y al MNI (Número Mínimo de Individuos) para los patrones de representación taxonómicos. Después se revisarán los patrones y los de alteración ósea de aquellos taxones más susceptibles de consumo antrópico (équidos, cérvidos, bóvidos y megafauna), para determinar y diferenciar que agentes intervinieron en las acumulaciones osteológicas analizadas, así como el grado de acción que tuvieron, con la finalidad de distinguir unas estrategias subsistenciales cinegéticas o carroñeras entre los homínidos del Paleolítico Inferior de la Península Ibérica.

\section{El Paleolítico INFerior EN LA Cornisa Cantábrica.}

Entre los yacimientos cantábricos de este momento la información disponible es muy escasa, de tal forma que sólo Cueva Morín (nivel 22), Lezetxiki y Castillo ofrecen datos. Aunque los materiales que presentan proceden de excavaciones antiguas y con un número de restos y de individuos escaso por lo que su muestra es poco representativa, y por tanto no pueden hacerse muchas precisiones sobre su fauna.

Según la información disponible en Lezetxiki se aprecia un predominio de oso, en sus dos niveles los cuales han sido interpretados como una ocupación de origen natural producida en los procesos de hibernación (Altuna, 1972). El 


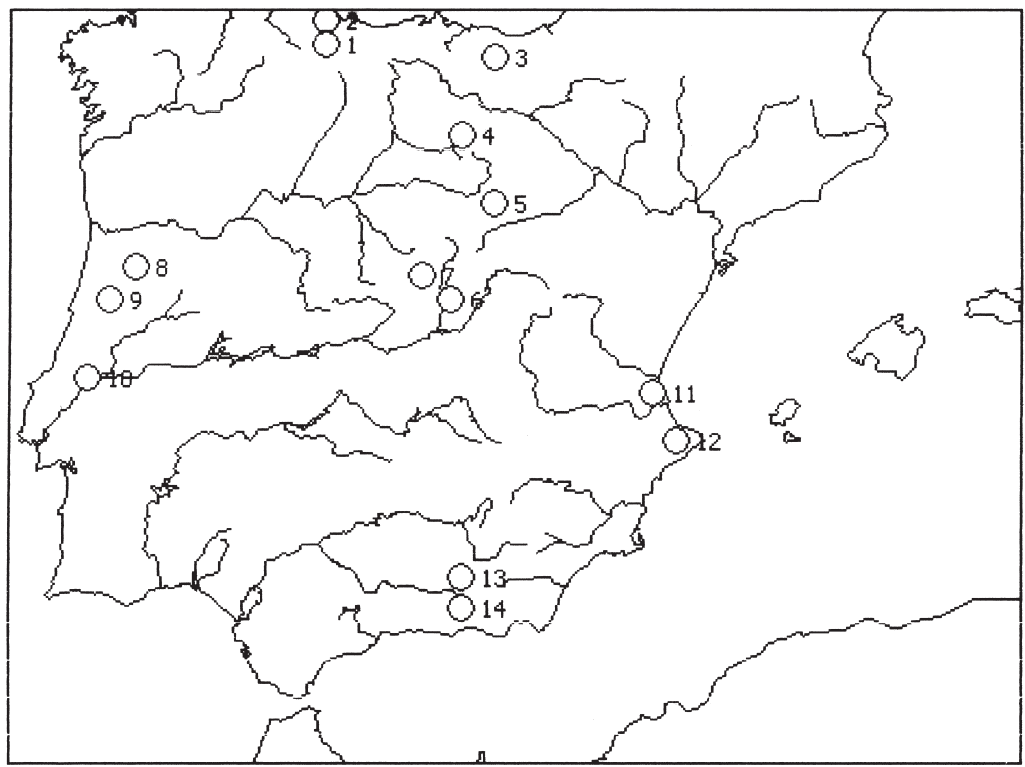

Figura 1. Yacimientos del Paleolítico In-ferior en la Península İbérica. Cueva Morín (1) (González Echegaray Ẻ Freeman, 1978), Castillo (2) (Cabrera, 1984, Klein \& Cruz Uribe, 1994; Dari, 1999), Lezetxiki (3) (Altuma, 1972), Atapuerca (Sima de los Huesos, Galería y Gran Dolina) (4) (Díez, 1992; Esteban, 1996; Díez, et al., 1999; Huguet et al., 1999), Torralba y Ambrona (5) (Binford, 1987; klein, 1987; Díez, 1992), Áridos 1 y 2 (6) (Santonja et al., 1980; Díez, 1992), Pinilla del Valle (7) (Díez, 1992), Meahalda y Fujaca (8) (Cardoso, 1993); Condeixa (9) (Cardoso, 1993); Almonda (10) (Cardoso, 1993); Bolomor (11) (Fernández, 1997); Corb

(12) (Sarrión, 1990); Solana del Zamborino (13) (Diez, 1992); Venta Micena (14) (Martínez Navarro, 1992).

segundo taxón predominante en este yacimiento son los bóvidos que en lo que al MNI se refiere, mantienen unos valores bastante equiparables a los del oso. En los del nivel 22 de Cueva Morín, el $N R$ es muy escaso (11 restos) y poco representativo destacando Equus y Bos.

En los datos que nos trasmiten Klein \& Cruz Uribe (1994) y Dari (1999) sobre el Castillo, se muestra una gran desproporción entre el $M N I$ y el $N R$, ya que el bajo $N R$ contrasta con el elevado MNI (Klein \& Cruz Uribe, 1994), no así en el estudio de Dari (1999) con un NR y $M N I$ muy escaso. Esto se debe a que el estudio de estos materiales corresponden a los obtenidos en las campañas de principios de siglo, en las que sólo se recogía los restos más identificables. Así se observa un predominio de ciervo y caballo.

En lo referente a la representación esquelética sólo disponemos de los retos del Castillo, el cual describe un predominio de elementos craneales entre los équidos y de los apendiculares distales (metápodos, falanges y huesos compactos), entre los cérvidos (Klein \& Cruz Uribe, 1994) los apendiculares proximales también están bien representados. En cualquier caso ambas representaciones carecen de valor, al estar totalmente alterados por los mecanismos de investigación, de hecho en los materiales estudiados por Dari (1999) los cérvidos sólo están representados por elementos cra- neales y los bóvidos por axiales.

En resumen la información zooarqueológica del Paleolítico Inferior cantábrico es hasta la fecha bastante fragmentaria y poco representativa, por lo que no permite establecer grandes precisiones sobre este aspecto y sobre el grado de acción que tuvieron los homínidos sobre estos restos, ya que no hay análisis tafonómicos adecuados que aporten luz sobre esta cuestión, tan sólo Dari (1999) indica la existencia de marcas de corte en los restos del Castillo, pero la muestra que analiza es poco representativa y no permite obtener grandes conclusiones.

\section{El Paleolítico Inferior en EL INTERIOR Y LA FACHAda ATLÁntica.}

\subsection{Los yacimientos menos representati- vos.}

A diferencia de lo observado en la Cornisa Cantábrica y de lo que luego se verá en la Vertiente Mediterránea, esta región si cuenta con un completo estudio zooarqueológico. A pesar de esto son numerosos los yacimientos del Paleolítico Inferior que carecen de análisis zooarqueológicos completos, debido a que muchos han sido excavados en intervenciones de urgencia (Santonja et al., 1980; Rus \& Vega, 1989; Sese \& Soto, 2000), en momentos antiguos (Sese \& Soto, 2000) o han sido exclusivas localizaciones 
en superficie (Montes, 1992; Utrilla, 1992). Sin embargo, algunos de estos yacimientos sin estudios zooarqueológicos detallados si cuentan con algunos datos que deben ser comentados.

En primer lugar destacar la asociación faunística de los yacimientos del entorno de Orce que luego serán completados con la información procedente de Venta Micena, de momento adelantar, que los hallazgos de Fuente Nueva III, Barranco León 5, Barranco del Paso y el propio Venta Micena, muestran una discutida presencia antrópica en fechas anteriores al millón de años en la Península Ibérica (Gibert, 1992; Martínez Navarro, 1992; Arribas et al. 1996). Aunque como se indicará más adelante la acumulación de alguno de estos yacimientos se debe en gran parte al protagonismo de algunos carnívoros.

En otros lugares de la misma región pero de fechas más recientes como Huéscar o Cúllar Baza destacan la pantera y los hiénidos entre los carnívoros, los bóvidos, el Paleoxodon antiqus el Dicerorhinus etruscus, el Hippopotamus major y el Praemegaceros cf solihacus entre los ungulados junto a los équidos que también están bien representados (Ruiz Bustos et al., 1982; Ruiz Bustos, 1984; Alberdi et al., 1989).

Entre los yacimientos correspondientes al entorno de Madrid, hay una síntesis bastante completa sobre la fauna pleistocénica realizada por Sese \& Soto (2000), en la cual puede percibirse el predominio de elefantes, équidos y bóvidos.

Junto a estos yacimientos hay otros como Ambrona, que ya será comentado más adelante que es conocido principalmente por las grandes acumulaciones de elefantes en el complejo inferior, y de équidos en el complejo superior (Santonja et al., 1996; Pérez González \& Santonja, $1997 \mathrm{a}, \mathrm{b})$.

Por último junto a estos yacimientos hay que referirse también a Cuesta de la Bajada (Teruel), con predominio de Equus, aunque también han aparecido otros taxones como Dicerorhinus hemitoechus, Cervus elaphus y Paleoxodon antiqus (Santonja et al., 1992; 1994; 2000).

\subsection{Los yacimientos más representati- vos: Patrones de Representación Taxonómico}

Desde un punto de vista taxonómico la información disponible es bastante abundante, ya que aparece en $N R, M N I$ y $M N E$ (Mínimo Número de Elementos), aunque este tipo de información sólo lo han calculado Díez (1992) y Huguet et al. (1999) para algunos niveles de Atapuerca. Por otro lado hay casos como los yacimientos portugueses donde la información disponible es escasa y muy fragmentaria, ya que sólo se refiere al número de restos, que, además, son muy reducidos.

En los yacimientos portugueses estudiados por Cardoso (1993) se aprecia como la mayoría corresponden a momentos de excavación antiguos por lo que sus materiales están sesgados de forma considerable. La mayoría de estos lugares se sitúan sobre terrazas y casi todos ellos tienden a mostrar una representación taxonómica muy poco variada con predominio de Equus, Cervus y Paleoxodon, por lo que el panorama de estos sitios no varía mucho respecto a los yacimientos peninsulares mostrados anteriormente.

$\mathrm{Al}$ contrario que las estaciones portuguesas, hay otros como el yacimiento granadino de Venta Micena que muestra un estudio zooarqueológico más completo, así no sólo muestran el análisis de los restos sino que también el del $M N I$, la representación anatómica y el del marco tafonómico. Sobre Venta Micena se ha escrito mucho dado la polémica que rodea a este lugar, así en numerosos trabajos se ha planteado la existencia de unas industrias en fechas anteriores al millón y medio de años (Gibert, 1992). También se ha intentado defender el franqueamiento del estrecho en estas fechas tempranas arguyendo la procedencia africana de ciertas especies faunísticas como el hipopótamo, la Pachicrocuta o el Cercopitecus (Gibert, 1992; Martínez Navarro, 1992; Arribas et al., 1996; Palmquist \& Martínez Navarro, 1996; Iglesias et al., 1998), pero este aspecto no se analizará en este trabajo, al ser discutido en otro anterior (Yravedra, 2000), al igual que el las industrias sobre graveras de los yacimientos de Orce.

En el análisis de los datos que presenta Martínez Navarro en diversos Trabajos (Martínez Navarro, 1992; Arribas et al., 1996) presenta el $N R$ y el $M N I$ una gran variedad taxonómica con cierto predominio de équidos y especies de tamaño grande, como el Megaloceros solihacus o los bóvidos, también la megafauna tiene un buen $M N I$, lo que indica una cantidad cárnica muy superior a la que podían aportar los demás ungulados. Junto a la abundancia de herbívoros, también los carnívoros tienen una buena representación, especialmente los hiénidos con Pachycrocuta brevirostris, esto ha permitido a los autores plantear determinadas hipótesis relacionadas con el protagonismo de los carnívoros en la acumulación osteológica de este sitio (Palmqiist \& Martínez Navarro, 1996).

Junto a esto, también se han documentado marcas de descarnación en el registro óseo que indican cierto acceso cárnico por parte de los 
homínidos, pero otros datos parecen mostrar como la acumulación de Venta Micena se debió más a un hecho biológico que antrópico (Palmquist \& Martínez Navarro, 1996; Gibert, 1992). Así la mayoría de los ungulados presentan alteraciones que los relacionan con el consumo de carnívoros, no sólo por las marcas de dientes sino que también por otros caracteres. Por ejemplo estos autores basándose en la edad han observado que las especies de mayor talla ofrecen un $M N I$ con predominio de infantiles o seniles, teniendo los animales de menor talla un mayor porcentaje de adultos. También han visto un predominio de presas con patologías, sobre todo entre las especies grandes. Lo que se corresponde con sus observaciones en la sabana, donde el $64 \%$ de los búfalos cazados por carnívoros muestran algún tipo de enfermedad, y entre las cebras el $24 \%$. En total supone un 22\% del total de las especies con rasgos de debilidad. Y según el sexo de los animales, entre los grandes destacan las hembras (de menor tamaño) en un $74 \%$ frente a los machos 26\% (de mayor tamaño). Por lo que según estos autores todo parece indicar que fueron los carnívoros los principales agentes responsables de esta acumulación. También confirma esto la gran abundancia de dientes deciduales entre los hiénidos, que mostraría la existencia de cubiles en torno a esta acumulación y la representación anatómica entre las que predominan los elementos craneales y apendiculares distales. Finalmente la escasa industria documentada asociada a fauna indicaría una acción antrópica testimonial a pesar de los yacimientos próximos de similar cronología como Barranco del Paso, Cortijo Alfonso, Barranco León, Fuente Nueva 3 y Cortijo de Doña Milagros con abundante industria (Gibert, 1992).

Junto a esta acumulación hay otros sitios como Cueva Victoria que ha sido interpretado como un cubil de carnívoros (Gibert, 1992).

En otro yacimiento como es el caso de Áridos I y II también se produce una acumulación faunística al borde de un río (Santonja et al., 1980), aunque a diferencia del yacimiento de Venta Micena si aparece gran cantidad de industria asociada a la fauna representada, de hecho sobre la industria se han documentado varios remontajes que indican una funcionalidad orientada al consumo de la fauna, en la que se desbastaban algunos núcleos para la extracción de lascas con las que descarnar los animales (Santonja et al., 1980). En todo este proceso los análisis zooarqueológicos de Soto (en Santonja et al., 1980) y Díez (1992) indican una asociación faunística con predominio de restos de conejo, pero que en lo refe- rente a la macrofauna destacan la representación de un Paleoxodon antiqus en conexión anatómica junto a otros taxones como bóvidos y cérvidos, igualmente en Aridos II también destaca la presencia de otro elefante. En el MNI la representación es bastante similar aunque frente al único paquidermo representado en Áridos II aparecen también dos individuos de bóvido y tres de cérvido en Áridos I. En la interpretación de estos dos yacimientos ha quedado claro el protagonismo antrópico en el aprovechamiento cárnico del elefante, aunque no se especifican las causas de muerte de dicho animal, aunque si parece que tuvo una muerte lenta y que lo hizo recostado sobre un lado. Por otro lado la edad del animal es de una edad intermedia aproximadamente de treinta años y que sufrió un intenso aprovechamiento por parte antrópica, lo cual podría relacionarlo con un episodio de muerte natural por causa desconocida o bien por medio de un acto cinegético antrópico, como el documentado por Cavalli-Sforza (1994) entre los pigmeos que tras herir a un elefante lo siguen el tiempo que sea necesario hasta su muerte.

En el yacimiento de Arriaga, un antiguo lecho meandriforme de un río, Rus \& Vega (1989) han documentado un episodio similar con restos de un elefante rodeado de industria, entre la que destacan ciertos elementos cortantes como cuchillos de dorso relacionados con su aprovechamiento cárnico. Junto a este taxón aparecen también restos de Cervus elaphus, Bos of primigenius, Equus caballus, y Dicerorhinus hemitoechus. Al igual que ocurría en Áridos la edad del elefante es de un adulto no senil, pero tampoco se precisa las condiciones de su muerte. Sobre su aprovechamiento los estudios tafonómicos parecen revelar que su consumo y descarnación no estuvo exento de corrientes leves de agua (Rus \& Vega, 1989).

Otros yacimientos con gran abundancia de paquidermos son los casos de Torralba y Ambrona, los cuales están rodeados de una gran controversia pues a lo largo de todo el siglo han sufrido múltiples interpretaciones. Sobre la problemática interpretativa que estos yacimientos y otros con representación de elefantes, Martos (1998) ha observado unas características comunes. Así, sobre una treintena de yacimientos del Pleistoceno Medio africano y europeo ha diferenciado dos tipos de acumulaciones, por un lado estarían aquellas en las que sólo hay un paquidermo acompañado o no de otros taxones, como por ejemplo los casos comentados de Áridos y Arriaga, y por el otro se refiere a las que poseen un gran número de individuos, como los casos ahora comentados de Torralba y Ambrona. 
Sobre los primeros como ya se indico anteriormente determinados elementos lo relacionan con un consumo antrópico temprano, ya que suelen mostrar un predominio de elementos cortantes entre la industria, y cierta ausencia de marcas de diente. Además, estos emplazamientos se dan en lugares fluviales de baja energía por lo que han permitido unas condiciones de conservación buenas y periodos de exposición variables, bien algo prolongados como se ha advertido en Arriaga (Rus \& Vega, 1989), o algo más cortos como en Áridos (Santonja et al., 1980).

Sobre el segundo tipo de yacimientos, Martos (1998) coincide en afirmar la complejidad de procesos que rodean a este tipo de yacimientos. Por poner un ejemplo se pueden destacar la multitud de interpretaciones que se le ha asignado a la fauna de Torralba y Ambrona, las cuales se han resumido en la tabla (1). Aunque no se va analizar todo este debate, si parece claro que ambos lugares constan de una compleja historia tafonómica rodeada de multitud de fenómenos,

\begin{tabular}{|c|c|c|c|c|c|c|c|}
\hline \multicolumn{8}{|c|}{ DIFERENTES INTERPRETACIONES SOBRE TORRALBA Y AMBRONA } \\
\hline $\begin{array}{c}\text { Marqués de } \\
\text { Cerralbo }\end{array}$ & Howell & Freeman & Kleim & Binford & Varios & Equipo actual & $\begin{array}{c}\text { Domínguez } \\
\text { Rodrigo }\end{array}$ \\
\hline $\begin{array}{l}\text { 1. Yac. Más Antiguo } \\
\text { de Euopa } \\
\text { 2. Las materias primas } \\
\text { son de a porte } \\
\text { antrópico. } \\
\text { 3. Es un cazadero } \\
\text { debido a que no hay } \\
\text { Conex. Anatómicas } \\
\text { No están rodados los } \\
\text { huesos, por lo que no } \\
\text { hay un aporte fluvial } \\
\text { 4. Se caza por Medio } \\
\text { de la emboscada, } \\
\text { tendiendo trampas en } \\
\text { los lugares donde las } \\
\text { presas beben. } \\
\text { 5. Imposibilidad de la } \\
\text { muerte por causas } \\
\text { naturales de las } \\
\text { especies. } \\
\text { 6. Ausencia de } \\
\text { evidencias de fuego. }\end{array}$ & $\begin{array}{l}\begin{array}{l}\text { 1. Relación } \\
\text { sincrónica } \\
\text { de ambos } \\
\text { sitios. } \\
\text { 2. Datac. } \\
\text { En el ciclo } \\
\text { del Riss del } \\
300 \text { o00 } \\
\text { 3. Es un } \\
\text { cazadero de } \\
\text { paquiderm } \\
\text { os y otros } \\
\text { taxones. } \\
\text { 4 Presencia } \\
\text { de Fuego } \\
\text { (Biberson) } \\
\text { 5 Se piensa } \\
\text { en lagunas } \\
\text { rodeada de } \\
\text { vegetación } \\
\text { herbácea } \\
\text { 6. H a y y } \\
\text { evidencias } \\
\text { de trabajo } \\
\text { de madera } \\
\text { y hueso. Ej } \\
\text { Las Puntas } \\
\text { Freeman } \\
\text { 7. Achelen. } \\
\text { 8. Asociac. } \\
\text { De Fauna e } \\
\text { industria } \\
9 \text { El Yac es } \\
\text { un depósito } \\
\text { charca- } \\
\text { trampa } \\
\text { 10 Ausenci } \\
\text { de alterac. } \\
\text { Postsedime } \\
\text { ntareas. } \\
\text { 11 Caza } \\
\text { por } \\
\text { conducción } \\
\text { de manadas } \\
\text { (Butzer) }\end{array}\end{array}$ & 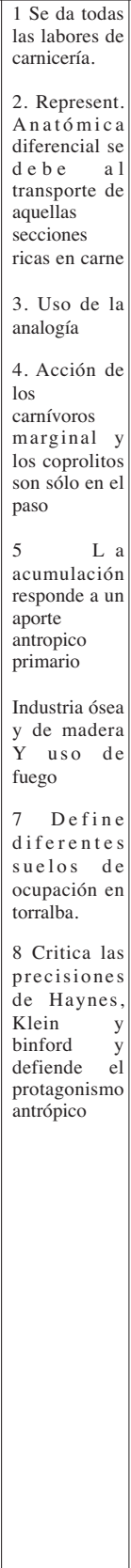 & $\begin{array}{l}1 . \\
\text { puede } \\
\text { haber } \\
\text { conducción } \\
\text { de } \\
\text { man ad as } \\
\text { porque } \\
\text { implicaría } \\
\text { un patrón } \\
\text { de } \\
\text { mortalidad } \\
\text { catastrófico } \\
\text { y el que } \\
\text { aparece es } \\
\text { atricional. } \\
\text { 2. Presente } \\
\text { acción de } \\
\text { carnívoros. } \\
3 \\
3 \\
\text { Representa } \\
\text { ción } \\
\text { Taxonómic } \\
\text { diferente } \\
\text { de la de } \\
\text { Aguirre } \\
4 \text { La Rep. } \\
\text { Anatómica } \\
\text { es el el } \\
\text { resultado } \\
\text { de muchos } \\
\text { fenómenos } \\
\text { algunos de } \\
\text { carácter } \\
\text { natural } \\
5 \\
5 \quad \text { H a y } \\
\text { Trampling } \\
6 \quad \text { de bió } \\
\text { darse un } \\
\text { importante } \\
\text { rol post- } \\
\text { morten. } \\
7 \\
\text { Importante } \\
\text { conservaci } \\
\text { on } \\
\text { diferencial } \\
\text { 8 Duda del } \\
\text { exclusivo } \\
\text { protagonis } \\
\text { mo } \\
\text { antrópico } \\
\text { 9 Piensa en } \\
\text { que las } \\
\text { acumulaci } \\
\text { ones tienen } \\
\text { lugar en un } \\
\text { lapso } \\
\text { cronológico } \\
\text { corto y } \\
\text { sincrónico }\end{array}$ & 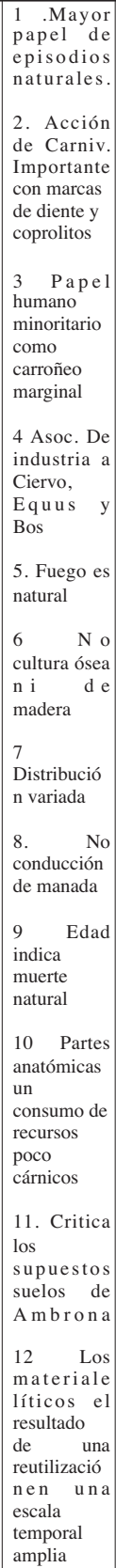 & 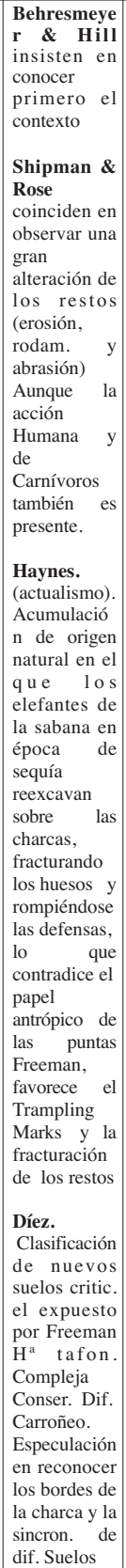 & 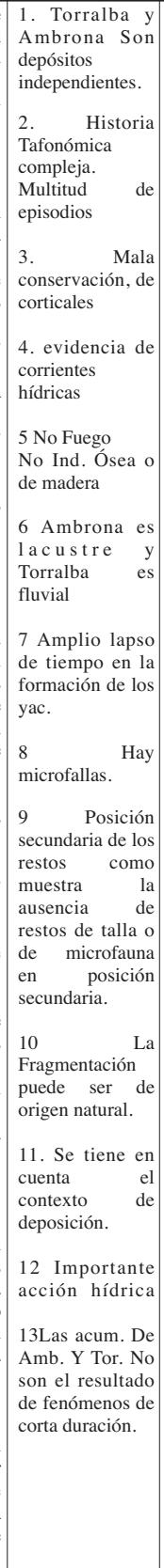 & 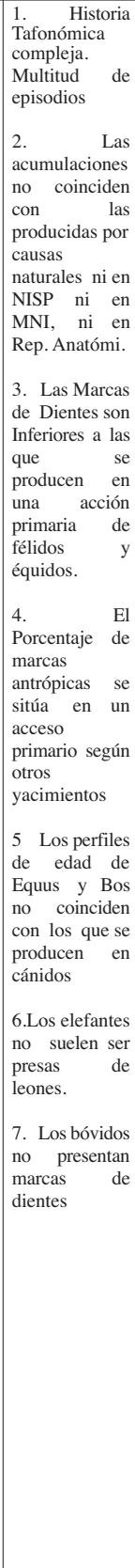 \\
\hline
\end{tabular}

Tabla 1. Correspondiente a las diferentes interpretaciones existentes sobre los yacimientos de Torralba y Ambrona, sacados de Martínez et al, (1997) y de Domínguez.Rodrigo (1998); Behresmeyer \& Hill (1980); Shipman \& Rose (1983); Díez (1992); Haynes (1988; 1991). 
tanto antrópicos como animales como de otros procesos naturales, sin que se pueda conocer exactamente qué grado de manipulación antrópica sufrió el conjunto. A pesar de esta circunstancia en numerosos trabajos se hacen determinadas afirmaciones sobre Torralba, interpretándolo como un lugar utilizado por los homínidos en la aprensión de cadáveres, o como un área de actividad carroñera de los homínidos sobre determinados recursos y otra serie de interpretaciones, que han sido ampliamente contrastadas por Domínguez-Rodrigo (1998).

En cualquier caso es considerable la compleja historia tafonómica, sedimentológica y arqueológica de Torralba y Ambrona. En la representación taxonómica se puede percibir un predominio de paquidermos, al abarcar el $58 \%$ de los restos según los datos de Díez (1992), seguido de los équidos con un $24 \%$ de los restos, los cérvidos con un $10 \%$ y los bóvidos con un $7 \%$, de tal manera que los demás taxones como los carnívoros estarían infrarrepresentados. En lo que se refiere al $M N I$, la representación es similar aunque los porcentajes son inferiores a los del $N R$, $34 \%$ para el Paleoxodon, $25 \%$ para los cérvidos, el $20 \%$ para los équidos y el $14 \%$ para los bóvidos teniendo los demás taxones una mayor representación que antes, aunque siguen siendo minoritarios. Por último en lo que a las edades se refiere parece predominar los individuos adultos en los casos en los que se ha podido establecer.

En el yacimiento de Pinilla del Valle, como en Venta Micena también hay una gran representación taxonómica. Así se observa un claro predominio de los cérvidos seguido de los équidos y los bóvidos. Igualmente es destacable la abundancia de carnívoros, entre los que predominan los hiénidos. Según el $M N I$ se observa una tendencia similar, aunque los carnívoros parecen reflejar unas proporciones mayores.

Esta abundancia de carnívoros, y el bajo número de elementos líticos parecen indicar que este yacimiento fue un cubil de hienas (Díez, 1992), ya que a la abundancia de restos pertenecientes a este taxón, hay que añadir los dientes deciduales de algunos especímenes, la representación anatómica (elementos craneales y apendiculares distales) y la abundancia de marcas de diente.

En Solana del Zamborino también hay cierta variedad taxonómica con predominio de las especies de entorno abierto, destacando la presencia de los bóvidos y équidos tanto en el $N R$ como en el $M N I$, seguida de los cérvidos y otros animales de tamaño medio, y por último los carnívoros, que son poco abundantes. La interpretación que Díez (1992) ha dado a este yacimiento es que se trata de un episodio con claro protagonismo antrópico sobre équidos y bóvidos, en el que los carnívoros tuvieron un papel secundario como carroñeadores. En las edades siguen predominando los adultos, aunque entre los équidos el número de infantiles iguala al de adultos. Además, la existencia de una zanja de $5 \mathrm{X} 1 \mathrm{X}$ $0,7 \mathrm{~m}$ en el Nivel $\mathrm{C}$ puede estar asociada a un episodio de caza. También Martínez Navarro (1992 b) piensa que el patrón de capturas de este yacimiento requiere un grado de selección humano mayor al de otros asentamientos como Venta Micena. Por lo que casi todos los autores coinciden en defender la auditoría humana de esta acumulación.

En los yacimientos de la sierra de Atapuerca se revisará en primer lugar la Sima de los Huesos, donde destaca la abundancia de úrsidos tanto en $N R$, como en $M N E$ y $M N I$. La interpretación de esta acumulación donde no han aparecido herramientas líticas ni ungulados, es que se debe a una colada de barro, según sugiere Díez (1992), Arsuaga et al. (1996), en el que sorprende la gran cantidad de número de restos humanos que aparece año tras año. Por otro lado algunos de los taxones documentados no suelen frecuentar las cuevas como los cánidos, por lo que debió ser aportados por otros individuos como otros carnívoros, ya que si se han documentado marcas de diente, ante esta interpretación podemos objetar, que por el mismo motivo que unos carnívoros introducen restos de otros carnívoros, entonces ¿por qué no aparecen ungulados en esta asociación?. Ante esto no podemos decir nada y tan sólo pensar que se trata de una acumulación de carácter natural.

Dolina, es otro de los yacimientos de la sierra de Atapuerca, el cual cuenta con diferentes estudios zooarqueológicos. En primer lugar destacar el de Díez (1992) sobre TD 10 y TD 11, el que este mismo autor ha realizado recientemente para TD 6 en Díez et al. (1999 A) y el de Esteban (1996) para TD 10 a, b, c. Según el $N R$ la representación taxonómica de estos niveles es bastante compensada entre los cérvidos, équidos y bóvidos, con un ligero predominio de los primeros en todos los niveles, especialmente en TD 6. A continuación siguen los équidos y bóvidos con valores muy similares, aunque son más abundantes los équidos. Finalmente los carnívoros son muy escasos. En el $M N I$ se aprecia en el estudio de TD 10-11 de Díez (1992) un aumento de los carnívoros y de los équidos que sobrepasan a los cérvidos. En TD 6 (Díez et al., 1999) y TD 10 A (Esteban, 1996), la proporción de cérvidos se corresponde más con el $N R$ antes comentado, aunque en TD $10 \mathrm{~B}$ y $10 \mathrm{c}$ aumenta la proporción de los bóvidos, por lo que 
la representación taxonómica difiere según sea en función del $N R$ o el $M N I$. Aunque en ambos casos hay predominancia de cérvidos, équidos y bóvidos, estando los carnívoros muy mal representados a excepción de los niveles TD 10-11 (Díez, 1992). En lo referente a las edades se observa un predominio de adultos, aunque se da una representación bastante compensada llegando en algunos casos a predominar los infantiles como en los équidos de TD 6 (Díez et al., 1999 a), o los bóvidos de TD 10 c (Esteban, 1996).

Desde el punto de vista interpretativo Esteban (1996) piensa que la acumulación de TD 10 a, b y c, se debió a una acción antrópica, en la que los carnívoros actuaron como agentes secundarios aprovechando los recursos abandonados por los homínidos, aunque la acción antrópica debió corresponder a varios momentos esporádicos sin ocupaciones continuas, por otro lado la variabilidad de las edades no permite hablar de selección en la adquisición de las presas.

Díez (1992) en otra interpretación coincide en identificar la baja incidencia de los carnívoros en TD 11 y TD 10, pero a diferencia de Esteban piensa que el acceso antrópico fue posterior al de los carnívoros.

Finalmente Díez et al. (1999 a) para los $7 \mathrm{~m}^{2}$ de TD 6 plantea que hubo una intensa acción antrópia sobre todos los taxones, los cuales fueron aportados por los homínidos a excepción de los carnívoros que murieron por causas naturales en la cavidad.

Por último en el nivel TD 4 (Díez et al., 1996 b) proponen que aunque es evidente la acción antrópica y de los carnívoros, la acumulación de dicho depósito se debe a una trampa natural, por la que los ungulados caían a un agujero donde morían y eran consumidos posteriormente por carnívoros y homínidos.

Una vez planteadas las diferentes interpretaciones de Dolina, hemos visto como varían estas según los niveles y los autores. Así, aunque se coincide en afirmar la baja incidencia de los carnívoros, no se piensa en lo mismo al definir el rol jugado por los homínidos, ya que en Díez (1992) propone un acceso secundario y en Díez et al. (1996 b, 1999 a) y Esteban (1996) se propone otro primario anterior a los carnívoros.

Para Galería como en Dolina contamos con varios estudios zooarqueológicos, así está el de Díez, (1992) para la unidad III (TG 10-11) en la que diferencia varias áreas (S001-S007), el de Díez et al., (1999 b) para esta misma unidad y el de Huguet et al. (1999) para la unidad II. Estos trabajos muestran, además, un intenso análisis en el que se mira el $N R$, el $M N E$ y el $M N I$. En todos ellos podemos observar como en el $N R$ los taxones predominantes son siempre los cérvidos y los équidos seguido luego de los bóvidos y los carnívoros que sin ser mayoritarios si tienen una representación bastante abundante. En el $M N E$ se da una tendencia parecida, ya que siguen predominando los mismos taxones, pero parece observarse como en muchos casos en los que los cérvidos predominaban sobre los équidos en el NR como S006 o TG 11 ahora los équidos tienen más $M N E$ que los cérvidos, por lo que indica un proceso de fracturación mayor en los cérvidos que en los équidos. En el $M N I$ hay una sobrerrepresentación de équidos y cérvidos, aunque ahora son los équidos los taxones predominantes ya que son más importantes que los cérvidos en la mayoría de los niveles.

En las edades destaca la gran abundancia de individuos infantiles sobre équidos y bóvidos, lo que puede haber influido en la menor fragmentación de dichos taxones, ya que los infantiles apenas tienen contenido medular $y$, por tanto, su aprovechamiento medular será menos acusado que en los adultos. En cambio en los cérvidos predominan los adultos y, por tanto, son más susceptibles de un consumo mayor.

En la fauna de Galería, Díez (1992) interpreta que la acumulación se debe principalmente a la acción de los carnívoros, teniendo los homínidos un mero papel secundario y carroñero. Para llegar a esta conclusión se basa en los patrones de edades, la representación anatómica, la escasez de herramientas líticas, la abundancia de carnívoros en niveles como S007 y en el predominio de marcas de diente sobre las marcas de corte. Aunque ahora no se analizarán estas cuestiones debido a que el análisis de las marcas y de la representación anatómica se desarrollará posteriormente. Por lo que de momento sólo se miraran los patrones de edad. Los cuales indican un predominio de infantiles en los taxones de mayor tamaño, frente a los de talla media que muestran una mayor proporción de adultos, por lo que se da un enfoque parecido al observado en Venta Micena (escasez de restos líticos, buena representación de carnívoros, predominio de infantiles en los taxones de talla mayor y de adultos en los de talla media-pequeña). En otro trabajo Díez (1995) propone que la adquisición de bóvidos y équidos se debió al carroñerismo antrópico, y que los cánidos fueron los principales aportadores de los cérvidos. Sin embargo, Domínguez-Rodrigo (1998) ha criticado ampliamente esta interpretación, ya que determinadas contradicciones intrínsecas a los planteamientos de Díez (1992, 1995) imposibilitan el carroñerismo de ciertos individuos. Así el aprovechamiento secundario de individuos infantiles es 
improbable según los estudios zooarqueológicos realizados (Blumenschine, 1986), y la representación anatómica existente también es contraria a un aprovechamiento secundario como luego se reflejará. Además, tampoco hay individuos infantiles entre los carnívoros que justifiquen la utilización del lugar como un sitio de cría. Por lo que la interpretación de Díez $(1992,1995)$ son bastante discutibles y, además, la propia industria lítica parece estar ligada a un aprovechamiento cárnico de la carcasa, lo que es incompatible con un carroñeo secundario de individuos infantiles y elementos axiales.

En el trabajo de Díez et al. (1999 b) sobre esta misma unidad, este autor realiza otra interpretación diferente. Así propone que la principal causa de esta acumulación fue una trampa natural abierta al exterior del karst, en la que los carnívoros actuaron como los principales manipuladores junto a los homínidos que utilizaron el refugio de manera esporádica. Pero a diferencia de trabajos anteriores reconoce el protagonismo antrópico en el acceso primario de ciertos animales grandes. Por otro lado se piensa que la cavidad fue utilizada por los homínidos como centro de descarnación, ya que como indica la descompensada representación anatómica a la que luego me referiré hay una gran desproporción entre unos elementos y otros, la cual no obedece a ninguna de las causas osteológicas, diagenéticas etc., si no que es una consecuencia de un transporte antrópico diferencial. De esta forma se observa alguna diferencia con respecto a la interpretación de Díez (1992, 1995), ya que ahora el responsable de la acumulación de esta unidad no corresponde a los carnívoros, y los homínidos no actúan como marginales carroñeadores.

En el trabajo sobre la unidad II de Huguet et al. (1999), se propone una interpretación bastante similar, ya que es en estos momentos cuando se forma la trampa natural que se desarrolla en la Unidad III, y así se piensa que la acumulación de este conjunto es una consecuencia de dicha trampa natural, aunque como en la Unidad III, también se produce una intensa acción primaria de carnívoros y homínidos sobre todos los taxones.

Para terminar esta parte podemos concluir que cada yacimiento tiene unos características propias y aunque aquí se ha adelantado parte de las interpretaciones que estos yacimientos han tenido, esta no podrá realizarse hasta que se analice los patrones de representación anatómicos y los estudios tafonómicos que a continuación se desarrollaran.

Para resumir la representación taxonómica a la que se ha ido haciendo referencia se ha podido apreciar como suelen predominar la mega- fauna, los cérvidos y los équidos. Pero esta representación ha de ser matizada, ya que la sobrerrepresentación de uno u otro dependerá del entorno al que pertenezca dicho yacimiento, de tal manera que los sitios situados sobre lugares abiertos en medios lacustres o fluviales como Torralba, Ambrona, Áridos, Arriaga, Venta Micena o los yacimientos de las terrazas del Manzanares y Portugal tienen cierta abundancia de elefantes o hipopótamos, aunque esto no impide que otros taxones como los bóvidos, cérvidos o équidos estén bien representados. Frente a esta representación, hay otros yacimientos situados en lugares cerrados, en cuevas o abrigos como los de Atapuerca y Pinilla del Valle que frente a esta abundancia de megafauna muestra un predominio de otros taxones como cérvidos y équidos. También hay que decir que esta generalización que se plantea sobre una representación taxonómica en función del yacimiento, es a priori algo cuestionable, ya que como hemos indicado la mayoría de los yacimientos sobre cueva responden a unas causas en las que no figuran los homínidos como los principales acumuladores de dichas asociaciones, sino que por el contrario se debe más a los propios carnívoros (casos de Pinilla del Valle y la Sima de los Huesos) o a trampas naturales (Galería), las cuales dificulta mucho el que animales de gran tonelaje llegue a dichas asociaciones.

Por otro lado en casos donde parece haberse dado un transporte de presas por parte humana como Dolina no parece mostrar gran abundancia de esta megafauna, lo que contrasta con la evidencia de yacimientos de aire libre. Lo que podría indicar que el consumo de los grandes herbívoros se producía in situ, allí donde moría el animal, trasladándose tan solo algunos restos en determinadas ocasiones. Por otro lado es destacable la ausencia de ciertos taxones que aparecen bien representados en los siguientes momentos del Paleolítico, me refiero en este caso a los cápridos, cuya presencia es mínima, lo que puede estar condicionado por dos factores. Las condiciones geográficas en las que se insertan los yacimientos en medio abiertos alejados de las zonas montañosas o abruptas en las que suelen vivir estas especies. Y las condiciones climáticas, las cuales parecen ser templadas y cálidas en la mayoría de los sitios

\subsection{Patrones de Representación Anatómica}

Como ya se indicó en la introducción estos patrones sólo se especificarán a aquellos taxones más susceptibles de consumo antrópico (équidos, cérvidos, bóvidos y paquidermos). 
Entre los cérvidos de Dolina no todos los niveles son igualmente representativos, pero parecen reflejar una tendencia similar de predominio de elementos craneales seguido de los apendiculares distales (Díez, 1992). Lo mismo ocurre en Pinilla del Valle, Solana del Zamborino, y en Áridos lo hacen los elementos craneales mientras que en Venta Micena lo hacen los craneales junto a los apendiculares proximales.

En Galería, como en Dolina no todos los niveles son igualmente representativos así en los que tienen un menor $N R$ como S.0.0.4 y S.0.0.5 parecen predominar los elementos craneales y los apendiculares proximales (húmero, radio, fémur y tibia) junto a los axiales, lo que contrasta con lo observado en Dolina. Esta misma observación también se produce en el $M N E$ de dichos niveles. En los que poseen un mayor $N R$ y $M N E$ destacan los elementos craneales, los apendiculares proximales y los axiales, teniendo las secciones apendiculares distales una presencia mínima (Huguet et al., 1999). En el estudio de Díez (1992) sobre la Unidad III se da una circunstancia similar aunque ahora aumenta la sobrerrepresentación de los axiales, que superan a los craneales en S.0.0.6. Esta representación puede deberse a que la proporción de los elementos craneales parece haber disminuido res- pecto al resto del conjunto ya que apenas supera el $20 \%$ de los restos y de los elementos.

En Torralba, sólo se ha considerado la agrupación de los diferentes niveles, ya que a escala individual la muestra es poco significativa. De todas formas la representación de casi todos los niveles corresponde con lo indicado en el global, sólo los niveles 4 a, 5, 6 y 7 denotan cierta diferenciación al mostrar una representación casi exclusiva de elementos craneales $(5,6,7)$ o de elementos apendiculares $(4$ a). Los demás casos se corresponden con el global, el cual indica cierto predominio de los restos craneales seguido de los axiales, los apendiculares distales y finalmente los apendiculares proximales. Es de destacar como en función del $N R$ o el $M N E$ esta representación varía algo, ya que en el $M N E$ las extremidades distales sobrepasan a los restos axiales al tiempo que los apendiculares proximales disminuyen más. Esto no se debe a que los elementos axiales sufran una mayor fragmentación, sino que es consecuencia del planteamiento metodológico seguido por el autor, ya que en el $N R$ bajo la agrupación de huesos largos se incluyen los metápodos, los cuales yo considero elementos apendiculares distales junto a falanges y otros huesos compactos. De esta forma se tiende acrecentar el número de restos de los apendiculares proximales frente a los distales. Por lo que siguiendo la representación

\begin{tabular}{|c|c|c|c|c|}
\hline $\begin{array}{l}\text { YACIMIENTOS } \\
\text { CIERVO NR }\end{array}$ & CRÁNEO/DIENTE & ESQ.AXIAL & $\begin{array}{l}\text { ESQ. APENDICUL. } \\
\text { PROXIMAL }\end{array}$ & $\begin{array}{c}\text { ESQ.APENDICUL. } \\
\text { DISTAL }\end{array}$ \\
\hline $\begin{array}{l}\text { Dolina (Total) } \\
\text { (Díez,1992) }\end{array}$ & $49 \% / 40 \%$ & $5,2 \%$ & $28,7 \%$ & $17,4 \%$ \\
\hline $\begin{array}{c}\text { Galería TG10B,TN6- } \\
\text { DA, TN6 }\end{array}$ & $53,5 \% / 43 \%$ & $16.7 \%$ & $22,3 \%$ & $7,4 \%$ \\
\hline $\begin{array}{c}\text { Galería TG 10C, TG } \\
\text { 10D, TN5 }\end{array}$ & $54 \% / 37,3 \%$ & $26,2 \%$ & $14,6 \%$ & $5,6 \%$ \\
\hline Galería S002 & $45 \% / 12 \%$ & $37,2 \%$ & $7,3 \%$ & $10 \%$ \\
\hline Galería S006 & $35,3 \% / 10,3 \%$ & $42 \%$ & $20,5 \%$ & $2,3 \%$ \\
\hline Galería S007 & $44,3 \% / 26,8 \%$ & $38,3 \%$ & $11,4 \%$ & $6 \%$ \\
\hline Pin.Valle (Ciervo) & $60 \% / 48 \%$ & $2 \%$ & $8,5 \%$ & $29,4 \%$ \\
\hline Pin. Valle (Gamo) & $74,6 \% / 65,9 \%$ & $1,1 \%$ & $5,5 \%$ & $18,8 \%$ \\
\hline Pin. Valle Cérvidos & $76,7 \% /-$ & $3,2 \%$ & $5 \%$ & $15,2 \%$ \\
\hline Torralba total & $45 \% / 2,9 \%$ & $22,5 \%$ & $14,5 \%$ & $21 \%$ \\
\hline Sol. del Zamborino & $50,4 \% / 40,1 \%$ & $7,3 \%$ & $12,4 \%$ & $30 \%$ \\
\hline $\begin{array}{l}\text { YACIMIENTOS } \\
\text { MNE CIERVO }\end{array}$ & CRÁNEO/DIENTE & ESQ.AXIAL & $\begin{array}{l}\text { ESQ. APENDICUL. } \\
\text { PROXIMAL }\end{array}$ & $\begin{array}{c}\text { ESQ. APENDICUL. } \\
\text { DISTAL }\end{array}$ \\
\hline Galería S002 & $46 \% / 19 \%$ & $37,1 \%$ & $10 \%$ & $6,7 \%$ \\
\hline Galería S006 & $32 \% / 17 \%$ & $40,4 \%$ & $25,5 \%$ & $2,1 \%$ \\
\hline Galería S007 & $43,7 \% / 26,5 \%$ & $39 \%$ & $9,9 \%$ & $7,3 \%$ \\
\hline Torralba total & $32,2 \% / 4,3 \%$ & $26,9 \%$ & $9,7 \%$ & $31,2 \%$ \\
\hline $\begin{array}{c}\text { Galería TG } 10 \text { (Díez et } \\
\text { al., 1999) }\end{array}$ & $42 \% / 23 \%$ & $35 \%$ & $14,3 \%$ & $9,1 \%$ \\
\hline $\begin{array}{c}\text { Galería TG } 11 \text { (Díez et } \\
\text { al., 1999) }\end{array}$ & $39,8 \% / 26,5 \%$ & $41,8 \%$ & $14,3 \%$ & $4,1 \%$ \\
\hline
\end{tabular}

Tabla 2. Patrones de Representación Taxonómica en los niveles más representativos de cérvidos según el NISP-MNE Esqueleto Axial (costillas, vértebras, escápula y vértebras), Apendicular Proximal (Húmero, radio, ulna, fémur y tibia), Apendicular Distal (Metápodos, carpos, tarsos y falanges). 
del $M N E$ habría un predominio de elementos craneales, seguido de los distales y finalmente los axiales y apendiculares proximales.

Por lo que resumiendo todos los yacimientos a excepción de Galería indican la misma tendencia, predominio de elementos craneales y apendiculares distales, seguido en menor instancia de los apendiculares proximales y los restos axiales (Tabla 2). Tal representación es compatible con la que dejan los carnívoros tras su acción, sobre todo cuando actúan como agentes secundarios. Sólo Galería indica una representación totalmente diferenciada al presentar cierto predominio de elementos axiales junto a los craneales y también Torralba con una situación más compensada.

En los bóvidos se da una situación parecida a la comentada en los cérvidos, así no todos los niveles son igualmente representativos, y sólo Pinilla del Valle y Solana del Zamborino son representativos.

Según los yacimientos, Dolina, Pinilla del Valle, Solana del Zamborino muestra una situación similar a la descrita en los cérvidos con preeminencia de elementos craneales y distales, en Áridos ocurre lo mismo que en el ciervo y en Venta Micena también En Galería el NR se ciñe principalmente a elementos craneales. Sólo S.0.0.6-7 y el MNE muestra una mayor proporción de elementos axiales, igualando el panorama observado en los cérvidos. Finalmente en Torralba predominen los elementos craneales seguido de los apendiculares proximales, los axiales y los distales. Si nos fijamos en el MNE esta situación se mantiene, aunque debido a lo comentado en los cérvidos en torno a los "huesos largos" la situación se hace más equilibrada entre los elementos proximales y los distales.

En los équidos la representatividad de los restos es superior a la contemplada en los bóvidos, pero como en aquel taxón se repite la misma tendencia, predominio de elementos craneales y apendiculares distales en Dolina, Pinilla del Valle, Solana del Zamborino y Pinilla del Valle. En Galería se observa un mayor número de niveles representativos, los cuales coinciden en mostrar dos patrones de representación diferentes. Así tal y como ocurría en los bóvidos y sobre todo en los cérvidos aparece un patrón de representación diferenciado según la unidad a la que corresponda el análisis. Así en la unidad II presentada por Huguett et al. (1999) están sobrerrepresentados los elementos craneales mientras que los demás elementos están muy mal representados, por el contrario en los dos estudios de la unidad III, la representación anatómica difieren en el grado de que los elementos axiales son mucho más abundantes tanto en el $N R$ como en el $M N E$ aunque con respecto a los cérvidos sus porcentajes han disminuido algo.

En Torralba la mayoría de los niveles tienen pocos restos y tienden a sobrerrepresentar los restos craneales aunque los demás elementos

\begin{tabular}{|c|c|c|c|c|}
\hline $\begin{array}{l}\text { YACIMIENTOS } \\
\text { EQUUS }\end{array}$ & CRÁNEO/DIENTE & ESQ.AXIAL & $\begin{array}{l}\text { ESQ.APENDICUL. } \\
\text { PROXIMAL }\end{array}$ & $\begin{array}{l}\text { ESQ. APENDICUL. } \\
\text { DISTAL }\end{array}$ \\
\hline Dolina Díez, (1992) & $72 \% / 63 \%$ & $11 \%$ & $6 \%$ & $12 \%$ \\
\hline $\begin{array}{c}\text { Galería TG } 10 \text { B, TN } \\
6 \text { DA, TN } 6\end{array}$ & $85 \% / 83 \%$ & $4 \%$ & $3 \%$ & $8 \%$ \\
\hline $\begin{array}{c}\text { Galería TG } 10 \text { C, TG } \\
10 \text { D, TN } 5\end{array}$ & $72 \% / 68 \%$ & $4 \%$ & $16 \%$ & $8,5 \%$ \\
\hline Galería S.O.O.6 & $48 \% / 38 \%$ & $41 \%$ & $4 \%$ & $6 \%$ \\
\hline Galería S.O.O.7 & $68 \% / 55 \%$ & $22 \%$ & $2 \%$ & $8 \%$ \\
\hline Pinilla del Valle & $53 \% / 49 \%$ & $3,2 \%$ & $8 \%$ & $36 \%$ \\
\hline Torralba 1 & $41 \% / 32 \%$ & $31 \%$ & $20 \%$ & $9 \%$ \\
\hline Torralba 3 & $47 \% / 40 \%$ & $22 \%$ & $21 \%$ & $10 \%$ \\
\hline Torralba Total & $44 \% / 36 \%$ & $22 \%$ & $25 \%$ & $9 \%$ \\
\hline Sol. Del Zamborino & $85,8 \% / 85 \%$ & $1,5 \%$ & $1,75 \%$ & $11 \%$ \\
\hline $\begin{array}{l}\text { YACIMIENTOS } \\
\text { MNE EQUUS }\end{array}$ & CRÁNEO/DIENTE & ESQ.AXIAL & $\begin{array}{l}\text { ESQ. APENDICUL. } \\
\text { PROXIMAL }\end{array}$ & $\begin{array}{l}\text { ESQ. APENDICUL. } \\
\text { DISTAL }\end{array}$ \\
\hline GALERÍA S.O.0.7 & $68,5 \% / 56 \%$ & $22,5 \%$ & $2,4 \%$ & $6,1 \%$ \\
\hline Torralba & $49 \% / 40,7 \%$ & $22 \%$ & $8,6 \%$ & $21 \%$ \\
\hline Galería TG 11 & $62,6 \% / 51,4 \%$ & $26 \%$ & $2,3 \%$ & $9,4 \%$ \\
\hline Galería TG 10 a & $51,1 \% / 44 \%$ & $28,2 \%$ & $14,9 \%$ & $6 \%$ \\
\hline
\end{tabular}

Tabla 3. Patrones de Representación Taxonómica en los niveles más representativos de Equus según el NR-MNE. 
también están bien documentados. En los niveles con mayor número de restos se observa la misma situación que en los taxones anteriores, ya que predominan los elementos craneales seguido de los axiales y los proximales manteniendo todos ellos valores muy parejos, aunque como ya se explico la muestra de apendiculares variará en función del estudio realizado (NR o $M N E)$. (Tabla 3).

Entre los paquidermos se aprecia como en algunos de los niveles de Torralba ya no son los elementos craneales los predominantes, ahora se da una situación nueva en el que todas las secciones a excepción de los elementos apendiculares distales mantienen unos valores muy similares. Una circunstancia que también se mantiene en los estratos menos representativos.

En otros yacimientos con menor número de restos como en Solana del Zamborino tan sólo aparecen restos craneales y en Áridos, Arenero del arrollo del Culebro o Arriaga parece haber gran abundancia de elementos axiales (Rus \& Vega, 1989; Díez, 1992; Sese \& Soto, 1991). Y en Venta Micena (Martínez Navarro, 1992) junto a los elementos craneales también están bien representados los elementos axiales y apendiculares proximales.

\subsection{Patrones de Alteración ósea en el Paleolítico Inferior.}

En venta Micena el conjunto está muy bien conservado y la sedimentación debió ser muy rápida (Gibert et al., 1992), esto ha permitido observar marcas antrópicas de descarnación y de fracturación sobre el conjunto osteológico (Gibert 1992; Martínez Navarro, 1992), de tal manera que de los 5000 restos analizados en Venta Micena, 300 presentan este tipo de alteraciones. Por otro lado los carnívoros son el principal agente acumulador de esta acumulación, no sólo por lo ya comentado en los apartados anteriores, sino que también por la gran abundancia de marcas de diente que aparecen. De tal manera que el $71 \%$ de los huesos parece haber sido fracturado por carnívoros y el $100 \%$ de las epífisis muestren marcas de dientes y mordisqueo (Arribas et al., 1996, Gibert et al., 1992). Estos datos indican que en Barranco del Paso y Venta Micena sí hubo actividad antrópica, aunque para Gibert (1992) es fruto del carroñeo, que también es reconocido por Palmquist \& Martínez Navarro (1996), Martínez Navarro (1995) y Gibert et al. (1992), que tras observar los patrones de edad, sexo y las patologías de los individuos cazados, piensan en un acceso carnívoro primario. Además, la existencia de dientes deciduales de hiénidos y la escasa industria localizada en venta Micena parecen indicar tres cosas. En primer lugar que la acción antrópica debió ser muy escasa, ya que el volumen de individuos animales localizados en este lugar es muy amplia frente a las evidencias de acción antrópica, muy escasas, aunque dado el alto tonelaje de ciertos especímenes como elefantes o hipopótamos y la alta disponibilidad cárnica que ofrecen plausibles de ser consumida, este no tiene por que dejar evidencias de marcas como ha indicado Creader (1983). Por lo que es posible que la acción humana fuera mayor de lo que pueda pensarse, aunque en ciertos estudios ha dejado de manifiesto la dieta principalmente vegetariana de los supuestos restos humanos de Venta Micena (Malgaba et al., 1992; Martínez Navarro, 1995). En segundo lugar creo que no hay bases suficientes para defender un protagonismo exclusivo de los carnívoros en la caza de ciertos taxones, ya que algunos de ellos como la megafauna carece de enemigos naturales, sin embargo el entorno de este yacimiento al borde de una charca puede ser un buen lugar para la muerte natural de estos individuos. En tercer lugar es evidente la intensa acción protagonizada por los carnívoros como muestran los patrones de marcas y de representación anatómica, junto a los dientes deciduales y otros condicionantes como los patrones de edad, las patologías de los especímenes presentados, que aunque no son del todo un rasgo diagnóstico sí puede ayudarnos a comprender el origen de esta acumulación sí los apoyamos en los otros datos tafonómicos. Los cuales según Arribas et al. (1996) hay un $71 \%$ de los restos con fracturas de origen animal, y todas las epífisis muestras de mordeduras.

Por lo que en definitiva la acumulación de Venta Micena sería un palimpsesto de múltiples procesos con especial incidencia de carnívoros, pero en el que también intervendría la muerte natural de algunas especies, la acumulación de hiénidos formando cubiles y la posible acción antrópica sobre determinados recursos (sin poder determinar si fue primario o secundario) aunque parece más probable la segunda opción.

A este respecto hay que decir que Palmquist \& Martínez Navarro (1996); Martínez Navarro (1995) y Gibert et al. (1992) no hacen referencia a que secciones anatómicas presentan marcas de corte, ni cuales son los taxones que las presentan. Por lo que no se puede definir que tipo de acción hicieron los homínidos. Lo que sí es seguro es que la gran biomasa presentada pudo ofrecer unas grandes posibilidades alimenticias.

En los casos de Torralba y Ambrona todo 
parece apuntar a una intensa historia tafonómica y sedimentológica muy variada, en la que según Shipman \& Rose (1983) el $66 \%$ de los restos presentan evidencias de rodamiento y erosión, junto a un alto grado de exposición subaérea sobre los materiales. También la fragmentación de los restos en opinión de Díez (1992) sería una consecuencia de la diagénesis, la presión del sedimento y otras circunstancias además de la propia acción antrópica. Por lo que la deposición de los restos no respondería a una posición primaria.

Por otro lado según Díez, $(1992,1995)$ el acceso antrópico sobre los restos de Torralba responderían a una acción secundaria destinada al aprovisionamiento de la carroña y los despojos cárnicos abandonada por los carnívoros. Sin embargo, tal y como ha observado DomínguezRodrigo (1998), determinadas circunstancias parecen indicar que los carnívoros no fueros unos actores tan importantes como pretende demostrar Díez, así el porcentaje de marcas de diente que presentan los restos óseos $(1,8 \%)$ está muy lejos del que debiera tener una acumulación producida por carnívoros, y determinados taxones como los bóvidos carecen de marcas de diente que indiquen un consumo animal primario de este taxón (Domínguez-Rodrigo, 1998) y otras especies como los elefantes carecen de enemigos naturales. Además, las evidencias de acción antrópica si parecen coincidir con la documentación de un acceso cárnico primario en otros yacimientos ya que el 1,7\% (Domínguez-Rodrigo, 1998), el 3,7 \% (Shipman \& Rose, 1983) y el 2,2 \% (Díez, 1992) de los restos presentan marcas de corte. Por lo que la interpretación de estos datos parece ser algo más complicada que la propuesta por Díez. Lo que sí es evidente y seguro es que sí se produjo un acceso cárnico antrópico y carnívoro sobre gran cantidad de recursos pero no se puede precisar como se produjo este. Aunque dada la alta representatividad de ciertos elementos como los axiales y los apendiculares proximales entre los paquidermos, équidos, cérvidos sí es probable un gran acceso a altas porciones cárnicas en estos taxones.

Los casos de Áridos y Arriaga ya se han comentado en el apartado 3.2. y parecen indicar un consumo antrópico primario, además la rápida deposición que se produjo en Áridos podría indicar una descarnación del elefante en un momento temprano tras su muerte.

En Pinilla del Valle aparece documentado un gran conjunto de alteraciones óseas, entre las que destacan los efectos postdeposicionales, los cuales aparecen en el $12 \%$ de los huesos, también hay pátinas en el $28 \%$ relacionadas con episodios de resedimentación (Díez, 1992), y huesos rodados que indican haber sufrido transportes hídricos producidos por la influencia de flujos y corrientes hídricas (Díez, 1992). De igual forma destacan las marcas de diente y la ausencia de estrías de descarnación y de industria lítica parecen indicar que este sitio fue un cubil de carnívoros.

En Solana del Zamborino como en Pinilla del valle el número de restos con alteraciones óseas es muy bajo en proporción al número de restos total. De igual forma muchos restos presentan una procedencia exsitu como reflejan ciertas alteraciones químicas, y las evidencias de corrientes hídricas, que se dejan sentir principalmente sobre los taxones de menor tamaño. Por otro lado la acción antrópica ha sido documentada a través de las marcas de corte y algunos huesos quemados pero en proporciones muy bajas. En algunas especies como en los cérvidos, los équidos y los bóvidos también hay alteraciones producidas por carnívoros por lo que también actuaron sobre el conjunto óseo, algo que se corresponde también con lo observado en el apartado de la representación anatómica. En lo que se refiere al aporte de carnívoros su aporte y consumo está únicamente relacionado con los propios carnívoros, ya que no presentan ninguna evidencia de manipulación antrópica.

La Sima de los Huesos no presenta marcas de corte por lo que el papel humano en esta acumulación no debió de ser importante a diferencia de los carnívoros, que si han dejado marcas de dientes. Por otro lado según García \& Arsuaga (1996), la acumulación de este yacimiento es consecuencia de un proceso de mortalidad natural de osos y zorros principalmente.

En Dolina como en algunos de los yacimientos anteriores también aparecen bastantes modificaciones óseas aunque en proporción el bajo número de marcas producidas por los carnívoros (1,1 \%) según Esteban (1996) parece indicar un acceso secundario de estos centrado en los taxones de menor talla (especies pequeñas e infantiles de taxones mayores), las cuales aparecen principalmente sobre las epífisis. También están documentadas las marcas de origen antrópico sobre el $2 \%$ de los restos, por lo que el aprovechamiento antrópico estuvo limitado a breves visitas esporádicas.

Díez (1992) coincide en identificar una baja incidencia de los carnívoros sobre TD 10 y TD 11 aunque observa un mayor porcentaje de marcas de diente $(6 \%)$ que Esteban. Sin embargo, opina que el acceso antrópico se realizó de forma secundaria. Esta paradójica conclusión contrasta 
con sus propios datos al identificar un $7 \%$ de marcas de corte sobre los restos óseos y al observar un predominio de estas sobre las costillas y elementos diafisiarios, los cuales suelen relacionarse con un aprovechamiento cárnico primario. Por otro lado también identifica marcas de diente sobre las epífisis, lo que indica un acceso sobre la carcasa por parte de los carnívoros en momentos tardíos en los que la carcasa está exenta de carne. Además, está misma interpretación tampoco encaja bien con la representación taxonómica presentada, ya que esta muestra un predominio de animales de talla media y de gran abundancia de individuos infantiles, que es incompatible con un acceso antrópico secundario y con las marcas antrópicas aludidas sobre las diáfisis. De la misma forma tampoco encaja dentro de esta explicación carroñera la representación anatómica, ya que en ella se ha observado un gran número de costillas y elementos axiales que no suelen pasar inadvertidos a los carnívoros. Por lo que como indica Domínguez-Rodrigo (1998) el origen de esta acumulación no puede deberse a carnívoros como los cánidos o los hiénidos. Igualmente de darse un aporte primario de carnívoros el porcentaje de marcas de diente sería mayor del documentado aquí.

También se han documentado otro tipo de alteraciones como las evidencias de la exposición subaérea que indican una exposición prolongada de algunos restos (Esteban, 1996), pero sobre todo destaca el manganeso que presentan algunos conjuntos como el nivel $\mathrm{b}$ de TD 10, donde el $60 \%$ de los restos presenta este tipo de alteración, lo que indica fuertes concentraciones de charcos de agua estancada que hicieron incómoda una ocupación prolongada de esta parte del yacimiento.

Para TD 6 Díez et al. (1999 a), han observado una intensa acción antrópica, en el que aparecen 156 huesos con marcas de corte frente a los 127 con marcas de diente, de un total de 1056 restos. Además, este mayor grado de acción antrópica se ha visto atestiguado por la gran fragmentación del conjunto donde el $74 \%$ de los restos es menor de dos cm y en el que el $28 \%$ presentan puntos de impacto que indican un gran consumo medular (Anconetani et al., 1996; Díez et al., 1999 a). Este acceso antrópico primario también es evidente según indica la situación donde aparecen las marcas de corte, situadas en el mayor de los casos sobre las diáfisis y los elementos axiales (costillas y vértebras), afectando a todos los taxones. Este aprovechamiento antrópico se ha producido sobre todos los taxones y parece ser anterior al realizado por los carnívoros como indican las marcas antrópicas localizadas en amplias secciones cárnicas. En lo referente a los carnívoros también ha quedado patente su acción sobre algunos elementos, especialmente en las metadiáfisis y las epífisis, y como ocurre con el patrón de aprovechamiento antrópico, también se da sobre todos los taxones aunque como agente secundario (Díez et al., 1996 b; 1999 a).

En Galería ya se indicó como los cérvidos sufrieron un proceso de fragmentación superior al de los otros taxones. En el estudio tafonómico de Díez (1992) para la unidad III (TG 10-11) destaca el contraste producido por el gran número de marcas de diente sobre las de corte, que evidencia una intensa acción de los carnívoros. Por lo que estos datos y otros a los que ya me referí le hacen interpretar este conjunto como un cubil de carnívoros, restringiendo la acción humana a un papel secundario y marginal. Sin embargo, esta hipótesis como ha indicado DomínguezRodríguez (1998) es bastante discutible, como ya se ha mostrado.

En primer lugar destacar que si predominan los individuos infantiles, el acceso secundario a estos sería inútil ya que tras el paso de los carnívoros no queda nada aprovechable pues carecen de médula y su consumo es sólo cuestión de minutos (Blumenschine, 1986). Igualmente en la industria lítica asociada predominan los elementos cortantes que suelen relacionarse con un consumo cárnico, y en un supuesto carroñeo este no se hubiera producido. En tercer lugar destacar que de ser una acumulación producida por carnívoros habría que especificar como se ha producido está, ya que no hay dientes deciduales ni nada que indique que fuera un cubil de cría, y por último destaca que la representación anatómica muestra un predominio de elementos craneales y axiales, con multitud de marcas de diente, las cuales suelen producirse en un acceso secundario de los carnívoros sobre las carcasas (DomínguezRodrigo, 1998). Así que más bien parece tratarse de una acumulación en la que los seres humanos actuaron como agentes primarios y los carnívoros como secundarios. Independientemente que el acceso humano fuera primario o secundario, la acción de los carnívoros es evidente pues un 20\% de los restos presenta marcas de diente frente al $1 \%$ con marcas de corte.

En el otro estudio de Díez et al. (1999 b) sobre esta misma unidad se propone que esta acumulación fue una trampa natural abierta al exterior del karst, en la que los carnívoros actuaron como los principales manipuladores junto a los homínidos que utilizaron el refugio de manera esporádica. Aunque se reconoce el protagonismo 
antrópico sobre el consumo primario de ciertos animales grandes. Que explicaría la descompensada representación anatómica de ciertos elementos axiales fruto de un transporte antrópico diferencial. Este acceso humano también puede percibirse a través de la fracturación de los restos óseos y ciertas muescas y puntos de impacto. De tal manera que dicha acción antrópica se centro sobre los équidos y cérvidos adultos, los cuales presentan bastantes marcas de corte sobre sus diáfisis (Díez et al., 1999 b).

Pero en la manipulación ósea de este conjunto destaca principalmente la acción de los carnívoros, que parecen dejar una mayor evidencia de su acción sobre los individuos de menor talla como los cérvidos y équidos infantiles que presentan una mayor alteración. La acción de los carnívoros parece centrarse sobre todo en las epífisis y las metadiáfisis, igual que ocurría en Dolina (Díez et al., 1999 a), y debió corresponder principalmente a cánidos según Díez et al., (1999 b). A pesar de este consumo antrópico primario es chocante la desproporción existente entre las marcas producidas por los carnívoros y las de corte mucho peor representadas.

Junto a estas explicaciones en las conclusiones de Díez et al. (1999 b) se propone que de darse un acceso antrópico secundario sobre los individuos adultos de talla grande se podría aprovechar las zonas craneales y axiales. Sin embargo, estas son las que menos posibilidades tienen de contener carne tras el acceso primario de un carnívoro, ya que los costillares son siempre lo primeros en consumirse (Blumenschine, 1986, Domínguez-Rodrigo, 1998), por lo que esta opinión de Díez et al. (1999 b) parece insostenible dada la representación anatómica documentada y los patrones de marcas.

Para la Unidad II Huguet et al. (1999) establece que el porcentaje de restos identificables asciende a un $19,4 \%$, por lo que no es un conjunto muy fragmentado. Aunque la conservación de los restos es bastante buena en los niveles inferiores TG 7, 8, 9 y TN 2, 3, 4 la intensa acción de agentes químicos ha dificultado su identificación e imposibilitado su análisis tafonómico, en cambio en el resto de la unidad este estudio se ha hecho permitiendo observar ciertas alteraciones como el rodamiento, las concreciones, los agrietamientos, el manganeso o el pisoteo. Así el 50\% de los huesos presentan evidencias de manganeso lo que ha permitido saber que en este momento Galería sufrió varios encharcamientos que imposibilitó su habitabilidad. También se ha observado gran cantidad de marcas de diente, alteraciones salivares, diáfisis cilíndricas que indi- can un intenso aprovechamiento por parte de los carnívoros (Díez et al., 1996 a; Huguet et al., 1999). Por otro lado la acción de los homínidos parece estar ligada a aquellos elementos más cárnicos como costillas, por lo que su acceso es primario y temprano a los animales. Algo que se ha visto corroborado también por las superposiciones de marcas de diente sobre marcas de corte en costillas y vértebras que indican un acceso primario humano y otro secundario carnívoro. Por el contrario en ningún caso se ha documentado lo contrario.

De esta forma en todos los estudios parece repetirse la misma tendencia. Un acceso antrópico primario (a pesar de lo indicado en Díez, 1992) seguido de otro posterior carnívoro. La acción de los carnívoros tiende a concentrarse en las secciones axiales y en los elementos apendiculares, lo que coincide con los elementos anatómicos más cárnicos y alimenticios, por lo que un consumo de estas secciones posterior al realizado por los ellos sería muy poco rentable e incompatible con un acceso secundario por parte antrópica. Por otro lado la acción antrópica se produce sobre los mismos elementos que han alterado los carnívoros, por lo que la única explicación de esto es que los carnívoros accedieran a los restos en un momento posterior al humano, manipulando las epífisis y fragmentos metadiafisiarios, con el fin de consumir el contenido graso de los extremos de este tipo de elementos, ya que si no tendría sentido las marcas de corte sobre estos huesos, ya que no quedaría carne que consumir.

Por otro lado destaca que gran parte de los restos óseos de animales pequeños no presentan casi marcas de corte, frente a las marcas de diente, lo que puede deberse a un aporte animal de este tipo de taxones. De hecho Díez et al. (1999 b) propone un papel predominante antrópico sobre los équidos y cérvidos adultos, los cuales son considerados como especímenes de talla media y grande. Resumiendo lo visto en Galería se puede pensar en una acumulación con un origen no muy claro, en el que las condiciones de ocupación no fueron muy favorables debido al encharcamiento del lugar, pero en el que diversos agentes actuaron sobre el conjunto. A esta misma conclusión ha llegado Rosas et al. (1999) que piensa en la cueva como un lugar de consumo más que en un lugar de ocupación, actuando sobre dicho lugar variedad de agentes. Así destaca en primer lugar el protagonismo antrópico sobre los animales de talla grande y mediana (cérvidos, équidos y bóvidos) seguido de un acceso secundario por parte de los carnívoros sobre estos mismos recursos y otros de menor tamaño. 


\subsection{Recapitulación}

Tras lo visto en este apartado parecen confirmarse las expectativas comentadas en los apartados anteriores así en Venta Micena se darían multitud de procesos en el que tendrían especial incidencia las acumulaciones producidas por carnívoros y los episodios de muerte natural, mientras que la acción humana en dicho lugar se limitaría a un acceso sobre altas porciones cárnicas procedentes de grandes herbívoros, aunque no hay un estudio tafonómico claro que especifique que taxones presentan alteraciones antrópicas.

En Torralba ocurriría un fenómeno parecido en el que estarían presentes multitud de fenómenos, y en el que dadas las malas condiciones de conservación no se pueden precisar que grado de manipulación antrópica y animal sufrieron los restos. En cualquier caso e independientemente del origen de los diferentes taxones sí parece seguro una alta representatividad de elementos cárnicos importantes, y que dada la representación anatómica existente si se pudo producir el acceso a estos recursos, aunque no se puede negar ni confirmar la existencia de ciertas estrategias cinegéticas. En los casos de Áridos y Arriaga ha quedado claro el temprano acceso antrópico que sufrieron dichas acumulaciones.

En Solana del Zamborino parece que si hubo un protagonismo predominantemente humano, aunque las evidencias de su acción no han quedado muy manifiestas, al contrario que lo ocurrido con los carnívoros que como agentes secundarios sí han alterado bastante el conjunto. Por otro lado se ha visto como el origen de algunos restos no corresponde a una posición primaria, y como ocurre en Torralba algunos elementos muestran cierta procedencia exsitu, por lo que la interpretación de este conjunto es más compleja de lo que realmente parece.

En los yacimientos de Pinilla del Valle y la Sima de los Huesos la ausencia de acción antrópica y la presencia de marcas de diente y otras peculiaridades de los carnívoros confirman el protagonismo de estos carnívoros en dichas acumulaciones, pero en cualquier caso las evidencias de su acción son menores de lo que cabría esperar.

En Dolina los diferentes estudios parecen confirmar el protagonismo antrópico que se desarrollo en la acumulación teniendo los carnívoros un papel secundario. Por otro lado la ocupación de este yacimiento como el de Galería, no debió ser muy favorable debido al encharcamiento de determinadas zonas del yacimiento.

En Galería también parece darse un papel predominantemente antrópico en la acumulación de ciertos restos, y así el acceso sobre los animales de talla media y grande corresponde a un aporte antrópico primario. Por otro lado la acción de los carnívoros se debe a un episodio secundario sobre estos taxones y primario sobre los de talla pequeña.

\section{El Paleolítico INFERior EN LA Vertiente MediterRánea.}

Como la Cornisa Cantábrica el número de yacimientos que presenta es bastante escaso, así sólo el estudio de Rueda (1993) sobre el yacimiento del Pleistoceno inferior de Incarcal parece indicar un origen natural de dicha acumulación, en el que el 54\% de los restos muestran fracturas de origen irregular, y en el que hay muchos restos que se conservan completos (13\%), igualmente entre la representación anatómica de dicho conjunto destacan los elementos axiales con un $60 \%$.

Otro yacimiento con una mayor representación es el yacimiento de Pedra Dreta en Sant Julia de Ramis en el que predominan los équidos y los rinocerontes, pero no se especifica que alteraciones ha sufrido el conjunto.

Ya en el País Valenciano se pueden destacar la cueva de Bolomor, donde predominan los équidos, los bóvidos y los cérvidos, pero donde también hay documentado otras como grupos el de la megafauna (Fernández, 1997). En el Corb predominan los cápridos (Sarrión, 1990).

\section{Conclusión}

Desde un punto de vista taxonómico destaca una relación completa entre la fauna representada y el entorno de cada yacimiento, pero se puede diferenciar una doble tendencia. En primer lugar destaca una asociación de gran megafauna (elefante e hipopótamo) junto al trienio Equus, Bos, y Cervus en las estaciones de carácter abierto, sobre medios de carácter fluvio-lacustres. Por el contrario en los emplazamientos cerrados sobre cuevas o abrigos hay un predominio del trienio aludido, con mayor presencia de ciervo o caballo según sea el clima más frío o templado.

Desde un punto de vista subsistencial se produce un amplio número de situaciones que parecen indicar un acceso antrópico rico en altas porciones cárnicas, bien por medio de episodios cinegéticos, o por medio de un carroñeo primario anterior a la llegada de otros carnívoros. Teniendo estos un papel secundario posterior a la acción de los homínidos, aunque en ocasiones 
también son los principales acumuladores de ciertos recursos, formando cubiles o reutilizando los emplazamientos de previa ocupación antrópica. Pero dados los análisis efectuados, quizás sea necesario realizar nuevos estudios tafonómicos que especifiquen las alteraciones óseas que sufren los diferentes taxones, ya que no se suele relacionar las especies con los diferentes tipos de marcas, y tan sólo se muestran los patrones de marcas de una manera global. Sólo en los yacimientos de Torralba, Galería, Dolina, y Solana del Zamborino se especifican los diferentes tipos de marcas por taxón, y sólo en Galería y Pinilla del Valle se indican la correspondencia de determinados tipos de marcas con los patrones de representación anatómica aunque en Galería no se especifica claramente a que taxón corresponde, por lo que no son unos datos muy precisos. Igualmente en ningún estudio se relaciona los porcentajes de marcas con el $M N E$, sino con el NISP, lo que da unos porcentajes diferentes de los reales, ya que la relación de estos datos con el $M N E$ es más preciso. De esta forma sería conveniente especificar en futuros trabajos tafonómicos tipos de marcas, relación de estas con cada taxón según el NISP y el $M N E$ y relación con cada sección anatómica.

\section{Bibliografía.}

Altuna, J., 1972: "Fauna de Mamíferos de los Yacimientos Prehistóricos de Guipúzcoa". Munibe XXIV

Alberdi, M.T.; Alcalá, L.; AZanza, B.; Cerdeño, E.; Mazo, A.; Morales, J. \& Sesé C., 1989: "Consideraciones Bioestratigráficas sobre la fauna de vertebrados fósiles de la Cuenca de Gaudix Baza. (Granada, España)". Trabajos sobre Neógeno y Cuaternario 11, 347-355.

Anconetani, P.; Díez, C. \& Rosell, J. 1996: "Intencional Bone Fracturing for marrow extraction in Atapuerca (Spain) and Isernia la Pineta (Italy). Lower Paleolithic sites". En III International Congress of Prehistoric and Protohistoric Sciencies. Forli 8-14 Septiembre. Tomo 2. 445-451.

Arribas Herrera, A.; Palmouist, P. \& Martínez NAVARRO, B., 1996: "Estudio tafonómico cuantitativo de la asociación de macromamíferos de Venta Micena". Comunicaciones de la II Reunión de Tafonomía y Fosilización. 27-38

Arsuaga, J.L; Bermúdez de Castro, J. M, Carbonell, E.; Cuenca Bastos, Lorenzo, C.; Pérez GonzÁLEZ, A. \& Rodríguez, X.P., 1996: "Los Yacimientos Pleistocénicos de la Sierra de Atapuerca". Itinerarios Geológicos desde Alcalá.153-173
Behrensmeyer, A. \& Hill (eds.), 1980: Fossils in the Moking: Vertebrate Taphonomic and paleoecology. Chicago University Press.

Binford, L. R., 1987; "Where there elephant hunters at Torralba". En The evolution of Human Hunting. Ed. M. H. Nitecki \& D. W. Nitecki. 47-104

Blumenschine, R.J., 1986: Early hominid scavenging opportunites. Implications of carcass availability in the Serengeti and Ngorongoro ecosystems. Oxford: Bar International Series 283.

Cabrera, V., 1984: El yacimiento de la Cueva del Castillo (Puente Viesgo Santander). Biblioteca Prehistórica Hispánica $n^{\circ} 22$.

Cardoso, J. L., 1993: Contribuçao para o Conhecimiento dos grandes Mamíferos du Pleistoceno Superior de Portugal. Comarca Municipal de Oeiras.

Cavalli-Sforza, L. F., 1994: Quiénes somos. Historia de la diversidad humana. Ed. Crítica.

Crader, D., 1983: "Recent single-carcass bone scatters and the problem of butchery sites in the archaeological record". En Animals \& Archaeology: Hunters and their prey, 107-142. B.A.R. Internatio-nal Series, 283. Oxford.

DARI, A., 1999: "Les grands mammiferes du site pleistocene superieur de la Grotte du Catillo: Étude archéozoologique: Donnes paleonyologiques, taphonomiques et palethnographiques". Espacio, Tiempo y Forma 12. 103-127.

DíEz, J. C., 1992: Zooarqueología de Atapuerca (Burgos), e implicaciones paleoconómicas del estudio tafonómico de yacimientos del Pleistoceno Medio. Tesís Doctoral. Univer-sidad Complutense de Madrid.

DíEz, J. C., 1995: "Acumulaciones faunísticas y homínidos en los yacimientos arqueológicos españoles". En Evolución Humana en Europa en los yacimientos de la sierra de Atapuerca. 557-604

Díez, J. C.; Moreno, V.; Rosell, J. \& Anconetani, P., 1996 a: "Sequence de la consommations des animaux par les carnivores au gisement de Galería. (Sierra de Atapuerca, Burgos)". En III Internationall congress of prehistoric and protohistoric sciencies. Forli, 814 Sept. (1996), Tomo 2. 1265-1270.

Díez, J. C.; FernándezJalvo, Y.; Cáceres, I.; Esteban, M.; Huguet, R.; Ibáñez, N. \& Rosell, J., 1996 b: "Zoo-archaeology and taphonomy of the early and Middle Pleistocene Sites of Sierra de Atapuerca (Burgos, Spain)". En III International Congress of prehistoric and protohistoric sciencies. Forli 8-14 Septiembre. Tomo 6. 1311-1314.

Díez, J. C.; Fernández Jalvo Y.; Rossells, J. \& CáceRES, I. 1999 a: "Zooarchaeology and taphonomy of Aurora Stratum (Gran Dolina, Sierra de Atapuerca, 
Spain.)". Journal of Human Evolution. Vol 37-No3/4. 623-652.

Díez, C; Moreno, V.; Rodríguez, J; Rosell, J. \& CÁCERES, I., 1999 b: "Estudio arqueozoológico de los restos de macrovertebrados de la Unidad III de Galería". En Atapuerca. Ocupaciones humanas y paleoecológicas del Yacimiento de Galería. Arqueología de Castilla y León. (ed.) Carbonell, E.; Rosas González, A. E̊ Díez, J. C. (1999). 265-281

Domínguez Rodrigo, M., 1998: "Tafonomía y Ciencia Ficción". Quadernos de Prehistoria i Arqueología de Castelló. Servei d'Investigations Arqueologiques $i$ Prehistóriques. 19. 7-25

Fernández Peris, J., 1997: Els Primeres habitants de les terres valencies. Diputació de Valencia

García, N. \& Arsuaga J. L., 1996: "The carnivora remains from the Sima de los Huesos. Middle Pleistocene Site". En III International Congress of prehistoric and protohistoric sciencies. Forli 8-14 Septiembre. Tomo 6: 1259-1264.

Gibert, J, 1992: Presencia humana en el Pleistoceno Inferior de Granada y Murcia. Proyecto Orce-Cueva Victoria (1988-1992).

GonZÁlez Echegaray, J. \& Freeman, L.G., 1978: Vida y Muerte en Cueva Morín. Instituto de cultura cantábrica.

HAYNES, G., 1988: "Longitudinal studients of African elephant death bone deposits". Journal of Archaeological Sciencie 14: 659-668.

Haynes, G., 1991: Mammoths, mastodonts and elephants. Biology, behavior and the fossil record. Cambridge University Press.

Huguet, R.; CÁceres, I.; Díez, J. C. \& Rosell, J., 1999: "Estudio tafonómico y zooarqueológico de los restos óseos de macrovertebrados de la Unidad G.II de Galería". En Atapuerca. Ocupaciones humanas y paleoecológicas del Yacimiento de Galería. Arqueología de Castilla y León. (ed.) Carbonell, E.; Rosas González, A. ED Díez, J. C.: 245-264.

Iglesias A., Gibert, J., Gibert, L. 1998: "La penetración de los homínidos por el Estrecho de Gibraltar en el contexto general de su dispesión". Gallaecia 17. 29-46.

KLEIN, R. G., 1987: "Reconstruging how early people explotation animals. Problems and Perspectives". En The evolution of Human Hunting. Ed. M. H. Nitecki \& D. W. Nitecki. 11-44

Klein R. G. \& Cruz-Uribe, K., 1994: "The Paleolithic mammalian fauna from the 1910-14 excavations at El Castillo cave (Cantabria)". Museo y Centro de Investigaciones de Altamira. Monografías 17. 141-158.
Malgaba, A.; Sofoni, S.; Subira, M.E. \& Carrasco, T., 1992: "Estudio preliminar de la paleodieta de los restos fósiles de Orce (Venta Micena, Granda), mediante el análisis de elementos traza". En Gibert, J (1992). Presencia humana en el Pleistoceno Inferior de Granada y Murcia. Proyecto Orce-Cueva Victoria (19881992). 189-197.

Martínez Moreno, J.; Mora, R.; Pérez, A. \& Santonja, M., 1997. "Bifaces junto a elefantes ¿Porque retornar a Torralba y Ambrona?".

Martínez Navarro, B., 1992: "Estudio cuantitativo y consideraciones paleo-biológicas de la Comunidad de Mamíferos del Yacimiento de Venta Micena". En Gibert, J (1992). Presencia humana en el Pleistoceno Inferior de Granada y Murcia. Proyecto Orce-Cueva Victoria (1988-1992). 155-188

Martínez Navarro B., 1995: "Orce Nuevas fronteras en paleontología y prehistoria de Europa". Revista de Arqueología 173. XVI. 6-17

Montes Bernárdez, R., 1992: "Los primeros grupos humanos depredadores en el Sur de la Península (Andalucía, Murcia y Albacete)". Munibe 43. 3-12.

Palmouist, P. \& Martínez Navarro, B., 1996: "Un modelo para diferenciar asociaciones de macromamíferos generados por mortandad gradual y catastrófica. Apli-cación al yacimeinto de Venta Micena". Comunicaciones de la reunión de Tafonomía y fosilización. 287-298.

Pérez González, A.; Santonja, M.; Gallardo, J.; Aleixandre, T.; Sese, C.; Soto, E.; Mora, R. \& VILla, P., 1997 a. "Los yacimientos Pleistocenos de Torralba y Ambrona y sus relaciones con la evolución geomorfológica del polje de conquezuela (Soria)". Geogaceta 28. 175-178.

Pérez González, A.; Santonja, M.; Gallardo, J.; Aleixandre, T.; Sese, C.; Soto, E.; Mora, R. \& Villa, P., 1997 b. "Actividad Humana y Procesos naturales". IV Reunión de Cuaternario. 235-247.

Rosas et al., 1999: "Contribución del yacimiento de Galería al cuaternario Ibérico". En Carbonell E.; Rosas \& Diez, J. C. (1999). Atapuerca: Ocupaciones humanas y paleoecología del yacimiento de Galería. 377391.

Ruiz Bustos, A., 1984: "El yacimiento paleontológico de Cúllar de Baza-I". Investigación y Ciencia 91. 20-29.

Ruiz Bustos, A.; Toro Moyano, I.; Martínez Suarez, E. \& Almohalla Gallego, M., 1982: "Procesos evolutivos durante el cuaternario Medio y Superior en las poblaciones de pequeños mamíferos del sur de la Península Ibérica. Condiciones climáticas que implican e importancia bioestratigráfica". Cuaderno de Prehistoria de la Universidad de Granada. 7. 9-23. 
Rus, I. \& Vega Toscano, G., 1989: "El yacimiento de Arriaga II. Problemas de una definición actual de los suelos de ocupación". Primeras Jornadas de Metodología e Investigación Prehistórica. Soria. 387-400

Santonja, M.; López Martínez, N. \& Pérez González, A., 1980: Ocupaciones achelenses en el valle del Jarama. Publicaciones de la Diputación provincial de Madrid.

Santonja, M.; Moissent, E. \& Pérez GonzÁlez, A., 1992: "Cuesta de la Bajada (Teruel) Un nuevo sitio del Paleolítico Inferior". Boletín del Seminario de Estudios de Arte y Arqueología. BSAA LVIII. 25-45

Santonja, M.; Moissent, E.; Pérez González, A.; Villa, P.; Sesé, C.; Soto, E., Mora, R.; Eisenmann, V. \& Dupre, M., 1994: "Cuesta de la Bajada un yacimiento del Pleistoceno Medio en Aragón. Arqueología Aragonesa". Gobierno de Aragón Departamento de Educaión y Cultura. 61-68

SAntonja, M.; Pérez González, A.; Mora, R.; Villa, P.; Sesé, C. \& Soto E., 1996: Estado actual de las investigaciones en Torralba y Ambrona

Santonja, M.; Pérez González, A.; Villa, P.; Sesé, C.; Soto, E., MORA, R.; Eisenmann, V. \& Dupre, M.,
2000: "El yacimiento Paleolítico de Cuesta de la Bajada (Teruel) y la ocupación humana en la zona oriental de la Península Ibérica en el Pleistoceno Medio". En Homenaje a E. Llobregat. Museo arqueológico de Alicante

SARRIÓN, I., 1990: "El Yacimiento del Pleistoceno Medio de la Cova del Corb (Ondara Alicante)". Archivo de Prehistoria Levantina vol. XX. 43-75.

Sesé, C. \& Soto, E., 2000: "Vertebrados del Pleistoceno de Madrid". En J. Morales (Coord) Patrimonio Paleontológico de la Comunidad de Madrid. Consejería de Educación de la Comunidad de Madrid. 216-243

Shipman, P. \& Rose, J., 1983: "Early hominid hunting, buchering and carcass-procesing behaviours: approaches to tha fossil record". Journal of anthropological Archaeology 2, 57-98.

Utrilla Miranda, P., 1992 "Aragón/Litoral Mediterráneo. Relaciones durante el Paleolítico". En Aragón/Litoral Mediterráneo. Intercambios Culturales durante la Prehistoria. Ponencias y comunicaciones (ed. Utrilla Miranda, P.) 9-53 